

\title{
A volta do Estado: aprendendo com os BIC? O Estado de transformação: volta, renovação, ou redescoberta?*
}

\author{
Return of the State: Learning from the BRICs? \\ The transformative state: return, renewal, or \\ rediscovery?
}

Linda Weiss

Resumo

A crise financeira global expôs a fraqueza da teoria econômica dominante e de políticas desregulatórias, maculou o modelo de laissez-faire do capitalismo, e precipitou uma reavaliação generalizada do papel do estado no controle do mercado. Enquanto a experiência dos BICs que oferece um poderoso modelo de ativismo do estado que transcende o Consenso de Washington, está em boa companhia. Um exame das experiências do passado e do futuro do Nordeste da Ásia (NEA) e dos Estados Unidos contesta, por um lado, vários mitos relativos ao pretenso desaparecimento do estado desenvolvimentista, e por outro, a chegada de um estado neoliberal. Enquanto o NEA oferece um modelo bem estudado do avanço industrial (catch-up) orientado pelo estado, que o neoliberalismo teria relegado ao lixo da história, os Estados Unidos fornecem um modelo substituto de supremacia tecnológica patrocinado pelo estado, que poucos desejam reconhecer.

Palavras-chave: Papel do Estado, Estado Desenvolvimentista, Estado Híbrido, BIC, Estados Unidos

\begin{abstract}
The global financial crisis has exposed the weaknesses of dominant economic theory and deregulatory policies, tarnished the laissez-faire model of capitalism, and precipitated a widespread reappraisal of the state's role in governing the market. While the BICs experience offers a powerful model of state activism that transcends the Washington Consensus, it is in good company. An examination of both past and recent experiences of North East Asia (NEA) and the United States challenges several myths concerning the alleged disappearance of the developmental state on one hand and the rise of a neoliberal state on the other. While NEA provides a well-studied model of stateguided industrial catch-up that neoliberalism was supposed to have consigned to the dustbin of history, the United States provides an under-studied model of state-sponsored technological supremacy that few wish to recognise
\end{abstract}

Key words: state activism, developmental state, hybrid state, BICs, United States 


\section{Introdução}

$\mathbf{N}$ a cultura política anglo-americana o Estado vem sendo há muito tempo objeto de ambivalência e desconfiança e até mesmo de demonização. Nos Estados Unidos, em particular, demonizar o Estado como incompetente, ineficiente ou corrupto e celebrar o mercado como uma panacéia para todos os fins chegou à condição de um esporte político nacional durante o mandato de Reagan. ${ }^{1} \mathrm{O}$ neoliberalismo e o corpo de ideias sobre maximização de livres mercados, por conseguinte, constituiu a ortodoxia política da economia dos Estados Unidos e de países mais avançados. Mais genericamente, a ideia do Estado como ator crítico da economia de mercado caiu em desuso nas últimas décadas quando o conceito de laissez-faire tomou conta da teoria do desenvolvimento. Na verdade, a idéia do Estado no papel desenvolvimentista tornou-se profundamente impopular nos círculos governamentais onde o desenvolvimento era mais necessário. Seguindo a moda, muitos analistas passaram a acreditar que a implementação de ideias neoliberais era abrangente, tirava os estados da governança industrial e - além de criar um ambiente de "negócios amistosos" deixava o mercado agir como bem quisesse. Assim, começou-se a enfatizar a subida do Estado neoliberal, aplicando esse rótulo tanto para os Estados Desenvolvimentistas (ED) do Leste Asiático quanto para os Estados que presidiam a chamada Economia de Livre Mercado da América.

Mas desde que a crise iniciada na América tornou-se global, temos visto um reaparecimento do papel econômico do Estado à medida que os governos do mundo todo intervêm maciçamente para apoiar mercados fracos, em declínio, e dar marcha à máquina do crescimento. Dos investimentos de bilhões de dólares dos Estados Unidos em iniciativas de energia limpa, ao apoio da França às empresas francesas com seu novo Fundo de Investimento Estratégico e iniciativas de "Grandes Empréstimos", e à agenda de "Nova Indústria, Novos empregos" da Grã-Bretanha, voltada para setores estratégicos com grandes verbas para investimento, o Estado está de volta nas economias avançadas, ou assim parece.

Na realidade, o Estado raramente, ou nunca, esteve fora do cenário (embora em muitos países em desenvolvimento as reformas neoliberais tenham causado danos sociais extensos e regressão política). Muito antes da crise, os Estados estiveram ativos na governança industrial. O que vemos hoje não é tanto o retorno do Estado, mas o resgate de sua legitimidade - e a redescoberta tardia do seu papel - como um ator crítico na economia de mercado (globalizada), e não menos crítico que os organismos internacionais, como o Banco Mundial e o FMI. Discuto brevemente três aspectos da crise de 2008 que foram essenciais para o resgate dessa legitimidade. Depois examino dois casos bastante distintos - o Nordeste da Ásia e os Estados Unidos - em que o Estado nunca saiu de moda e cuja existência vai completamente contra as máximas neoliberais, e faço uma rápida menção aos BICs, onde, de forma semelhante, não houve uma grande crise financeira "que justificasse a volta do Estado". 


\section{Liçōes do Grande Colapso Financeiro}

Como muitos comentaristas do mundo político e acadêmico hoje reconhecem, o Grande Colapso Financeiro (GCF) não causou apenas imenso dano à economia mundial. Também expôs a grande precariedade dos pacotes de reforma neoliberal, que incluía desregulação, privatização e liberalização. As reformas das políticas exemplificadas pelo Consenso de Washington - tais como liberalização do mercado de capital e financeiro - foram as mesmas medidas que ajudaram a propagar a crise em todo o mundo. Os países mais integrados na economia global foram os mais afetados, embora alguns em menor escala, por terem sistemas financeiros mais cuidadosamente regulados, redes de segurança social adequadas, e reservas cambiais (por ex. Escandinávia, Austrália, Leste Asiático, China, Brasil).

A crise também aplicou um grande golpe na teoria econômica prevalecente. Em particular, minou a crença fundamentalista em mercados liberados -- a ideia de que os mercados corrigem-se e sustentam-se por si mesmos. Como escreve Paul Krugman, "a crença em mercados financeiros eficientes cegou muitos, se não a maioria dos economistas, quanto à emergência da maior bolha financeira da história. $E$ a teoria do mercado eficiente também teve um papel significativo de, a priori, inflar essa bolha".2 O FMI e o Banco Mundial endossaram recentemente esse ceticismo sobre o livre mercado mudando sua abordagem ao desenvolvimento. O Banco Mundial, por exemplo, passou do alerta aos países em desenvolvimento de que a política industrial não funciona, à recomendação do seu uso visando a gerar empregos, compensar o overstretch industrial, e ter uma participação no mercado de energia verde. ${ }^{3}$ Até mesmo o FMI apresentou uma política revertendo sua posição sobre controles de capital. Restrições a entradas de capital, incluindo taxações, são hoje declaradas um item "legítimo" da "caixa de ferramentas de geração de políticas".

Afora o dano à teoria econômica, a crise deu uma clara demonstração do papel crítico desempenhado pelos estados de resgatar e sustentar o sistema de crédito. Pela primeira vez desde a ascensão da ortodoxia neoliberal, na década de 1980, uma reavaliação do papel econômico do estado está a caminho.

\section{Lição Um: Impactos da valorização do estado da globalização}

Uma lição da história passada e recente de liberalização financeira, incluindo respostas ao GCF, é que o Estado vem desempenhando um papel crítico para salvar a economia das crises financeiras. Intervenções para garantir depósitos, concessão de empréstimos, e nacionalização de bancos com injeções de capital, têm sido regularmente implantadas para restaurar o sistema de crédito em decorrência de liberalização financeira. ${ }^{5}$

O ponto a ser enfatizado é que a integração global tem profundos efeitos de desestabilização, que por sua vez faz com que o Estado intervenha rotineiramente. Crises financeiras vêm sendo um traço recorrente do capitalismo global há mais de 
200 anos. A intervenção do governo no mercado financeiro para resgatar os sistemas de crédito tem sido a regra, não a exceção. Se os resgates públicos e as nacionalizações não são novidade na história do capitalismo, é porque a globalização - fluxos financeiros internacionais - aumenta a volatilidade e a instabilidade. Como lembra o falecido economista histórico Charles Kindelberger, a inerente instabilidade das finanças globais assegurou uma necessidade recorrente de uma autoridade nacional (ou internacional) para agir como principal investidor, financiador e emprestador de última instância. Portanto, a lição um é que a integração financeira global não marginaliza o Estado - ao contrário, valoriza seu papel de "gerenciador do mercado".

\section{Lição Dois: O modelo de la̛issez-faire de capitalismo nocivo}

A outra lição é que a economia global não privilegia um modelo de capitalismo (mas certamente pode tornar o modelo de 'laissez-faire' não funcional). No passado, houve quem acreditasse que o "modelo americano" exemplificava o melhor mix de instituições e políticas. Era o modelo de "boa governança" que o resto do mundo deveria copiar. Mas a marca americana de capitalismo - especificamente associada ao seu setor financeiro de laissez-faire - está hoje maculada por ter causado extraordinário dano a si mesmo e ao resto do mundo.

Nas palavras de Joseph Stiglitz,'Pessoas do mundo todo costumavam nos admirar pela nossa economia, e nós lhes dizíamos que se quisessem ser como nós deviam conceder poder ao mercado. Hoje, a questão é que ninguém mais tem respeito por esse tipo de modelo em razão dessa crise. E é claro que isso põe em jogo nossa credibilidade. Todos hoje acreditam que estão sofrendo por nossa causa.7 "O laissezfaire terminou" declarou o presidente Sarkozy. Até mesmo os líderes chineses, por muito tempo céticos a respeito dos esforços dos Estados Unidos de vender as vantagens de seu chamado modelo de livre mercado, observaram ironicamente que 'os professores passaram a ter alguns problemas.'

Assim sendo, tanto dentro quanto fora do país a versão dos Estados Unidos de capitalismo perdeu o brilho ideológico e a credibilidade originadas do poder e do sucesso financeiro - brilho que ajudou a vender seu Mercado Livre, marca desregulada do capitalismo lá fora, não apenas para países em desenvolvimento, onde os Estados Unidos lideravam a campanha de acabar com controles governamentais das finanças e da indústria.

Em termos da contestação de idéias, portanto, podemos considerar a GCF um momento crucial da liderança americana, marcada pelo fim da era de defesa inquestionável do capitalismo de mercado livre. Como observou Francis Fukuyama, ideias são, afinal de contas, umas das mais importantes exportações da América -- e a quintessência do ideário americano, que passou a dominar o estágio global desde o início da década de 1980, foi uma certa visão de capitalismo, que advogava que a desregulação, os mercados livres, e um governo firmemente amparado, seria a 
máquina do crescimento econômico. ${ }^{9}$ Ao invés disso, a crise prolongada - e as maciças fraudes e fracassos dos mercados financeiros que causaram essa crise (para não falar no maciço resgate do setor financeiro pelos contribuintes americanos) - desacreditou essa visão de capitalismo de Mercado Livre/Consenso de Washington, e abriu caminho para um interesse renovado no papel dos Estados e mercados.

\section{Lição Três: O "Estado Neoliberal" enquanto mito}

Mais genericamente, foi preciso uma crise financeira para a ideia do Estado neoliberal triunfante - uma crença antiga - passar do status de um saber inconteste para o cerne da questão a ser discutida. Levados por respostas do governo à crise financeira, muitos "minimizadores (da importância) do Estado" fizeram uma pausa; dessa forma o Estado está vivendo um momento de reavaliação. Assim, uma terceira conseqüência da crise não é tanto a "volta do Estado" quanto a redescoberta de que os Estados ainda importam para a governança industrial e estabilidade social.

A seguir, examino como e por que o Estado - muito antes da crise financeira e em contraste com as expectativas criadas por debates sobre globalização e neoliberalismo - permaneceu no centro da governança industrial (que hoje inclui a chamada 'governança do conhecimento" ou "inovação"). Antes de falar sobre a experiência dos $\mathrm{BIC}$, que atualmente atrai muito interesse, discuto dois grandes casos de ativismo do governo que escaparam de um devido escrutínio - um envolvendo os Estados em Desenvolvimento do Leste Asiático, o outro seu absoluto oposto ostensivo -- os Estados Unidos. Embora sejam exemplos importantes e característicos de governança industrial, esses dois casos foram profundamente deturpados em debates recentes e amplamente marginalizados em relatos influenciados pelo paradigma neoliberal reinante.

\section{Redescobrindo o Estado (não-neoliberal)}

Na compreensão mais abrangente do papel que o Estado passou a desempenhar na governança industrial contemporânea, o Estado ativo, o Estado que governa o Mercado, retirou-se de cena nas três últimas décadas -- em conformidade com a crença nas prescrições neoliberais para sucesso econômico, ou sob restrições impostas pelas pressões dos mercados abertos.

Nesse paradigma mercado-cêntrico, as duas maiores provas (de força dos mercados e falência dos Estados) foram por um lado os Estados Unidos, como principal exemplo de uma abordagem de mercado livre para inovação e transformação econômica, e por outro os Países em Desenvolvimento do Leste Asiático (Coreia, Taiwan, Japão), apresentadas rotineiramente como exemplificação da mudança de economias guiadas pelo Estado para economias dirigidas pelo mercado. Ambas as "evidências" baseiam-se nas profundas descaracterizações da relação Estado-mercado nos seus respectivos cenários. Vejamos por que. 


\section{Após o catch-up}

Embora a pesquisa sobre o papel do Leste Asiático no catch-up industrial tenha sido substancial, foi acompanhado de um esforço para eliminar conceitualmente a experiência de como os Estados se comportam depois que o catch-up é atingido, e como a maioria das indústrias conhecidas está funcionando. A suposição central foi de que quando as empresas de uma nação passam de imitação a inovação resta pouca coisa para o Estado fazer, além de suprir fundos para pesquisa e desenvolvimento. As políticas industriais de catch-up que focalizaram classicamente a promoção de indústrias noviças através de tarifas protecionistas, crédito subsidiado e controle de preços, têm muito menos relevância nas economias desenvolvidas. Nem são apropriadas para economias crescentemente integradas, caracterizadas por abertura comercial e mobilidade de capital. E por aí vai a argumentação.

No ambiente de pós-catch-up dá-se mais importância à capacidade das empresas de inovar - quer isso envolva, no sentido mais amplo, um contínuo upgrade de produtos e processos que utilizem novas combinações de knowhow existente, quer, no sentido mais restrito, signifique inovações revolucionárias e criação de produtos inteiramente novos. Em ambos os casos, o aumento de capacidade das empresas de inovar é fundamental.

Entretanto, a distinção básica não é o envolvimento versus o não-envolvimento do Estado, mas a extensão na qual os Estados são mais ou menos proativos nesse processo de inovação (chamado "governança do conhecimento", que continuarei a incluir aqui sob "governança industrial"). Assim, podemos imaginar um espectro que vai de um extremo mais passivo de governança industrial [o chamado Estado "neoliberal"], simplesmente através de gastos com "pesquisas", a um extremo mais ativo em que os Estados seriam envolvidos em um, alguns ou todos os seguintes elementos: adquirir nova tecnologia (protótipo/desenvolvimento do produto); suprir uma demanda assegurada por essas inovações; criar um conjunto de problemas tecnológicos a serem solucionados pela indústria; gerar invenções públicas/propriedade intelectual para empresas privadas explorarem; assumir private equity em empresas inovadoras; planejar com a indústria novos padrões tecnológicos para flanquear concorrentes estrangeiros, e assim por diante. Dessa forma, tendendo ao extremo mais passivo do envolvimento do Estado encontramos a Grã-Bretanha; passando para o meio e mais além observaríamos diversos Estados do mundo desenvolvido e mercados emergentes, que usam um ou mais desses instrumentos para reduzir risco e incerteza das empresas no processo de inovação.

Porém, de especial interesse, é o extremo mais ativo (ou proativo) do espectro, pois é aí que encontramos os Estados Unidos. O ativismo americano de inovação pode realmente surpreender, em vista da caracterização desse país como arquétipo da economia de mercado livre. Entretanto, são eles os que mais se destacam no uso de todas essas formas "ativas" de governança industrial - mas de maneiras 
não-convencionais (falaremos mais sobre isso abaixo). Devemos juntar a esse cenário de ativismo do Estado os antigos ED do Leste Asiático, cujas ambições "desenvolvimentistas" encontraram novas aplicações além da fase de catch-up. Veremos primeiro o caso dos ED.

\section{Olhando para o Leste: a estranha não-morte do Estado Desenvolvimentista}

Durante pelo menos uma década, apesar da grande evidência ao contrário, os declinistas persistiram em difundir o pernicioso mito da morte dos ED. A democratização, a liberalização financeira, a crise da moeda asiática e o catch-up industrial foram considerados, em várias ocasiões, os agentes básicos da dissolução dos ED do Nordeste da Ásia. Quaisquer que sejam suas diferenças, a maioria das versões da "tese declinista" prevê convergência ou transformação para alguma coisa semelhante a um Estado neoliberal.

Na realidade, as ambições e estratégias dos ED do Leste Asiático estão vivas e passam muito bem. Mas antes de entrarmos na contra-evidência, façamos uma breve pausa para considerar como os declinistas puderam criar um cenário tão errado. Há três importantes erros conceituais (e metodológicos), habilmente mencionados pela primeira vez no notável paper conceitual de Elizabeth Thurbon, 'Why the Declinists are Wrong..$^{10} \mathrm{O}$ primeiro erro, e o mais importante, foi generalizar a partir do específico e, pior ainda, generalizar (para todos os ED) a partir do caso específico da autoritária Coreia do Sul, na década de 1970. Isso efetivamente congela o modelo dos ED no tempo e no espaço, portanto o quê deve ser um instrumento analítico amplamente aplicável torna-se tão inútil quanto um dispositivo heurístico.

O segundo erro, relacionado ao primeiro, foi não distinguir (ou melhor, confundir) entre o tipo ideal e o case empírico. Tendo como origem o "tipo de ED" do caso historicamente específico da Coreia autoritária, na década de 1970, os ED são tipificados pelo controle burocrático de cima para baixo, com uma coordenação altamente centralizada e um conjunto específico de políticas. Por definição, portanto, qualquer desvio desse "modelo" é interpretado pelos declinistas como a saída dos ED do cenário global.

O terceiro erro foi (muito curiosamente) ignorar o trabalho pioneiro dos ED (i.e. de Chalmers Johnson no Japão e dos tigres do nordeste asiático), esquecendo a característica básica que torna o desenvolvimentismo distinto (logo, diferente da política industrial simples); ou seja, a abordagem consistentemente estratégica do crescimento e portanto a mentalidade presente dos autores da política que efetivamente diz: não é a quantidade de crescimento que conta, mas o tipo de indústrias nas quais um país investe é que importa para a segurança e prosperidade nacionais de longo prazo. Essa mentalidade desenvolvimentista expressa-se no que Chalmers Johnson (1982) e mais tarde Robert Wade chamaram de "política 
industrial estratégica"; sua ênfase está no constante upgrading e transformação da estrutura industrial para preencher o gap tecnológico ${ }^{11}$. Voltando ao ponto, de forma ligeiramente diferente, quase todos os governos alegam que desejam crescimento - pelo menos nos agregados. O quê distingue os países desenvolvimentistas é sua ênfase sistemática no crescimento orientado, com foco na manipulação da estrutura industrial para promover o desenvolvimento de setores específicos.

Fazer um teste com a ideia dos declinistas no cenário pós-catchup atual da Coreia ou de Taiwan é instrutivo. Longe de estar debilitada, a ênfase na estratégia permanece forte, mas com as devidas diferenças em relação ao passado. Para começar, há uma mudança evidente nas metas estratégicas, que se traduz em priorizar a promoção dos setores de crescimento emergente e as tecnologias correlatas (em vez de construir indústrias já existentes, a partir do zero). Esses Estados aproveitam-se do escopo proporcionado por regras da OMC para construir capacidade de inovação nativa nos setores de conhecimento intensivo, e para remodelar as instituições mais apropriadas às tarefas mais especializadas tecnologicamente. Na era do pós-catchup os novos ED do Leste Asiático também continuam a implementar alguns instrumentos políticos do passado - considerados marcos de sua capacidade de transformação - tais como uso de "orientação administrativa" e estabelecimento de "padrões de desempenho" em troca de apoio governamental. Os esforços efetivos da Coreia na última década para construir uma liderança doméstica em telecomunicações, a fim de vencer os competidores estrangeiros, é um dos casos. Um breve exame de sua estratégia esclarece qualquer dúvida de que o Estado permanece sendo um ator crítico no avanço internacional do setor privado.

\section{Coreia: de telecomunicações a energia verde}

Para que ninguém duvide da persistência das ambições desenvolvimentistas da Coreia do Sul, o caso das telecomunicações é instrutivo. Seu relato ilustra como o modelo coreano foi renovado para atender ao desafio da industrialização, baseada no conhecimento em uma economia aberta. Assim que a crise financeira asiática amainou, o Ministry of Information and Communication (MIC) anunciou sua visão estratégica de uma Coreia eletrônica, chamada Cyber Korea 21. A visão Cyber deu continuidade a uma primeira ênfase na construção de banda larga e promoção de setor privado, e estabeleceu uma meta de 'Fazer dos Coreanos os Melhores Usuários de Computador (e internet) do Mundo". Foram incluídas no currículo educacional extensas instruções para computador e seu uso, e tornou-se obrigatória a instalação de banda larga extensiva por todo o país. ${ }^{12}$ Vale dizer que a motivação não era simplesmente maximizar a disponibilização de banda larga a seus cidadãos (o que ocorreu, chegando ao status mundial de "número um"). Por trás da estratégia existe uma meta maior: tornar-se um inovador avançado, industrializado e exportador líder em tecnologia de telefones celulares, smart phones, set-top boxes, e outros elementos 
da revolução digital. Embora por volta de 2000 a Coreia tivesse chegado à liderança mundial em hardware para celulares (e em 1998 se tornado o maior fabricante de memória DRAM), ela dependia de licenciamento de tecnologia estrangeira, o que resultava em um fluxo de saída de divisas. Os coreanos tiveram de se libertar dessa dependência e produzir (e internacionalizar) seus próprios padrões. O papel do Estado nesse processo mostrou ser crítico em várias fases.

Assim, o segundo capítulo da revolução de Tecnologia de Informação e Comunicação (TIC) da Coreia explica, em primeiro lugar, como as empresas coreanas conseguiram libertar-se da dependência da tecnologia de telefones celulares dos Estados Unidos e dos pesados pagamentos de royalty para a Qualcomm da América (cujo desenvolvimento tecnológico original, aliás, foi respaldado por verba federal). Em segundo lugar, descreve como as empresas coreanas construíram suas próprias novas tecnologias core e as incorporaram em produtos que alcançaram extensivos mercados.

Essa intrincada história é muito bem contada por Sung-Young Kim, e apresentada aqui de forma concisa. ${ }^{13}$ No centro da realização de conquistas havia o papel de coordenador do Ministry of Industry and Commerce (MIC), apoiando as ambições de upgrading tecnológico de empresas domésticas e atingindo uma posição proeminente na guerra por padrões tecnológicos, no final do qual a Qualcomm desistiu da "corrida" contra os coreanos, cujo padrão havia catapultado as empresas coreanas para a liga mundial de comunicações móveis. Ao atingir esse objetivo (parte de um projeto maior de desenvolvimento nacional em TI, iniciado em 2004), o MIC concebeu uma estratégia master, envolvendo a promoção de um novo padrão de software de comunicação móvel (conhecido como WIPI), seguido de um novo padrão de broadcasting móvel desenvolvido na Coreia (conhecido como DMB, uma tecnologia que transmite broadcasts via torres de transmissão em terra para telefones celulares -- o que exigiu a criação de novas instituições e formas inovadoras de colaboração Estado-indústria. A estratégia do MIC constou de quatro elementos principais:

Subsidiar uma parceria público-privada de P\&D para alavancar a capacidade de inovação e recursos financeiros de empresas coreanas e encorajá-las a aplicar rapidamente e comercializar tecnologia de Digital Multimedia Broadcasting (DMB) antes dos concorrentes estrangeiros entrarem no mercado. É importante dizer que esse apoio foi condicionado a padrões de desempenho a serem atingidos, nesse caso, o progresso observável no cumprimento das metas de P\&D.

Assegurar um mercado doméstico inicial para fabricantes de $\mathrm{DMB}$, induzindo a cooperação de prestadores de serviços, e usando a autoridade do Estado sobre a alocação para retardar a entrada de padrões concorrentes estrangeiros (mais uma vez, com o respaldo condicionado à capacidade das empresas coreanas aprimorarem rapidamente suas tecnologias. 
Transformar a tecnologia de DMB em um padrão internacional, ao assegurar postos para coreanos em cargos influentes dentro de organismos normativos internacionais, e ao fazer campanha do DMB através do patrocínio de um fórum normativo público-privado. A abordagem coreana em relação à normalização internacional concentrava-se em assegurar mercados de longo prazo para empresas domésticas. Como observa Kim, “Promover as exportações apenas por meio de subsidio está se tornando cada vez mais redundante, mas é proibido pelo acordo de subsídios da OMC. Em um setor verdadeiramente "global", como telecomunicações, os padrões adotados pelos parceiros comerciais são bases determinantes para se saber se um mercado de exportação existirá ou não."14

Embora a OMC tenha dificultado aos novos países em desenvolvimento a escalada industrial, a história é bem diferente para os países que já atingiram um nível mais alto e que procuram desenvolver uma indústria baseada no conhecimento intensivo. Como já mencionei em outro lugar, para os países mais adiantados há grande espaço para manobra. ${ }^{15} \mathrm{Na}$ verdade, o Estado coreano dominou completamente esse espaço, trabalhando proativamente dentro da estrutura da OMC para acelerar upgrading tecnológico (usando todos os instrumentos formais e informais à sua legítima disposição) e para assegurar mercados de longo termo para empresas coreanas através de uma conjunção coordenada de normas.

Apesar de alguns registros acharem que a "centralização" burocrática é a chave do modusoperandido Estado desenvolvimentista (Leste Asiático), não deveríamos criar um fetiche de uma característica organizacional, seja centralizada ou descentralizada, pois o que realmente importa é o que ela faz - a meta que a organização pretende atingir. Em termos institucionais, o neo-Estado Desenvolvimentista é menos centralizado mas não menos desenvolvimentista. Em vez de uma burocracia responsável (ou uma agência piloto), a política da indústria estratégica estará provavelmente estruturada em uma agência "quase-piloto" tecnologicamente especializada, onde o foco é criar áreas de crescimento tecnológico (ao invés de estabelecer setores industriais completos, como aço, carros etc -- que já estão implantados!) e assim recrutar mais pessoal com treinamento técnico do que generalistas. Menos centralização tampouco significa menos isolamento de interesses comerciais especiais, pois os responsáveis pela política governamental (no caso, coreana) mantêm uma certa distância da interação direta, valendo-se das ações e feedback regulares por parte de outras agências governamentais. Conforme diz Kim, "Acima de tudo, uma agência piloto central pode ter sido valiosa em um período de construção da nação, onde uma agência governamental [com jurisdição] suprafinanciando e promovendo recursos para indústrias - indo de finanças até construção naval - foi necessária. Contudo, à medida que um país se aproxima de uma posição de liderança tecnológica, uma agência quase-piloto especializada que tenha jurisdição sobre um campo tecnológico é da maior utilidade."16 
Em suma, a capacidade transformadora específica do Estado coreano parece não estar em dúvida - ao contrário, parece bem exercitada e longe de isolamento. Depois de efetivamente implementar uma política voltada para indústrias nascentes nos setores de conhecimento intensivo de TI e comunicações, a Coreia mudou o foco para energia renovável e criação de indústrias"verdes". Na estratégia nacional possivelmente mais abrangente até hoje (fora a da China?), o recém-criado Ministry of Knowledge Economy (MKE) ${ }^{17}$ expôs a nova visão nacional para a "Coreia de Crescimento Verde". Com um orçamento proposto equivalente a dois por cento do PIB, o governo coreano está implantando uma estratégia de desenvolvimento verde para atingir três resultados: (a) transformar o paradigma de energia doméstico (fazendo dos coreanos os maiores usuários do mundo de produtos de energia verde); (b) desenvolver um cluster de novas indústrias que ofereçam novas competências, empregos, e mercados de exportação (por ex. para tecnologias verdes, como baterias alimentadas por energia solar, combustíveis de biomassa, veículos híbridos, casas autoenergizadas, e assim por diante); e (c) elevar o status internacional da Coreia (como um "modelo" para o resto do mundo). ${ }^{18}$ Se o caminho trilhado pela Coreia serve de guia para o futuro, podemos esperar um uso mais criterioso da sua capacidade de transformação.

Em termos mais amplos, podemos estender prontamente a discussão para outros "países desenvolvimentistas" clássicos (i.e. Taiwan e Japão). Focalizei a experiência coreana em razão do seu valor metodológico quanto à estratégia, ou seja, seu papel de evidência central para o caso de declínio. Ao examinarmos de perto essa evidência, o mito do declínio dos ED é desfeito.

\section{Olhando para o "Norte": O Estado Americano \& a Economia de Livre Mercado}

Tanto a narrativa oficial quanto a teoria convencional descrevem os Estados Unidos como uma economia liberal - ou de "livre mercado". Os empreendedores individuais são seus heróis e a livre empresa é a chave da capacidade inovadora da nação. O endeusamento do falecido Steve Jobs por suas inovações na Apple exemplificam essa narrativa unilateral. A narrativa mais influente e popular atribui a capacidade de inovação revolucionária à tradição americana de empreendedorismo e à cultura de correr riscos, na qual indivíduos criativos que trabalham por iniciativa própria, expõem novas idéias e novos produtos com base na sua própria ingenuidade e ações ousadas. As palavras do CEO da Microsoft ilustram nitidamente a narrativa dominante, na qual a inovação americana é um processo independente do Estado:

A indústria de computadores está liderando a economia da nossa nação no século vinte e um... Não há na América uma indústria mais criativa, mais viva e mais competitiva. E o incrível é que tudo isso ocorreu sem o envolvimento do governo (Bill Gates: 1998) ${ }^{19}$. 
Não é bem assim. Olhando mais atentamente, vemos outro lado das inovações de empresas como a Apple e a Google - para mencionar apenas duas famosas criações dos Estados Unidos - ou seja, uma miscelânea de tecnologias que surgiram a partir de patrocínio caro e sustentado pelo Estado. Das inovações do GPS ao telefone celular, ou do mouse ao ultimo assistente pessoal de controle de voz (SIRI) do novo Iphone, aos programas de busca Google Earth e Google - todas apresentam um elemento em comum. Essas tecnologias, como a internet e a revolução da TI que a precederam, emergiram a partir de um paciente investimento federal em inovações de alto risco focalizadas (basicamente) em objetivos de segurança nacional. Na verdade, a máquina de inovações dos Estados Unidos é resultado de uma complexa interação de iniciativa pública e privada, que surgiu e evoluiu a partir das cinzas da Segunda Guerra Mundial e continua até o presente.

\section{O Estado Híbrido}

Então, o que responde pela capacidade de transformação da América? De onde vêm suas inovações revolucionárias? Na exposição que se segue, faço um rápido apanhado sobre isso no meu próximo livro, no qual examino as fontes de segurança nacional das inovações e empresas dos Estados Unidos. ${ }^{20}$ Retratado tipicamente como um Estado "fraco", com capacidade mínima de transformação ou interesse, os Estados Unidos têm sido mal compreendidos nos debates recentes sobre globalização e capitalismo comparativo. Entendo que para compreender a relação Estado-mercado no capitalismo americano, devemos começar com a parte ou partes do Estado americano ligado à segurança nacional. É a isso que me refiro como Estado de Segurança Nacional (National Security State - NSS), ao mesmo tempo mais amplo que a esfera militar e mais estrito que o Estado em si. Embora centrado na preparação da defesa, o NSS é muito mais abrangente que o setor de defesa ou o Departamento de Defesa. Além do seu núcleo militar, o NSS engloba vários outros componentes criados no auge da Guerra Fria para buscar, transmitir ou endossar inovações, a fim de assegurar supremacia tecnológica. ${ }^{21}$ Basicamente, o NSS é melhor entendido como uma Empresa de Tecnologia que cresceu depois de 1947 em resposta à percepção de uma persistente ameaça externa vinda da União Soviética. Quanto a esse impulsionador "externo", vale notar que o NSS pode ser comparado aos ED do Nordeste Asiático, pois eles também emergiram em resposta a uma persistente ameaça à segurança, porém baseando sua legitimidade mais amplamente na busca de segurança nacional através de aprimoração econômica, ou "catch-up" industrial. Vivendo nos meandros da Guerra Fria e na presença de uma ameaça estável e real à sua porta, exerceram uma pressão incomum na busca por segurança, através da construção de poderio econômico.

Para compreender de que forma o NSS funciona como uma máquina estratégica de inovação, empreendedorismo e networking node para projetos de governo-indústria, e por que suas extensas ligações com o setor comercial são raramente visíveis, e 
muito menos examinadas, eu introduzo o conceito de hibridização e exploro sua complementaridade institucional a um conjunto de valores nacionais "anti-estadistas".

Para começar, há mais no modelo americano de capitalismo e no Estado americano do que se pode ver sob a ótica do livre mercado neoliberal. Por algum tempo foi isso que formou o núcleo da força econômica real da América e continua a sustentar seu status de hegemonia tecnológica.

Esse "algo mais" é um formidável sistema de inovação tecnológica, que resultou em virtualmente todas as principais tecnologias de amplo uso, nas quais a indústria americana se baseia hoje (pensem nos computadores, softwares, semicondutores, máquinas a jato, biotecnologia, e as recém-emergentes nanotecnologia, robótica e energia verde). Apesar da visão da economia americana "independente do Estado", suas autoridades federais construíram o mais fantástico sistema de tecnologia de transformação do mundo, com base em inovação orientada para segurança nacional. Embora haja quem goste de falar de uma política industrial oculta, isso não é estritamente correto. O NSS busca a supremacia tecnológica a fim de manter a primazia geopolítica da América, não por competitividade econômica. Contudo, vale notar que na busca desse objetivo estratégico, o Estado de Segurança Nacional, que cresce desde a década de 1980, teve de admitir considerações comerciais explícitas quanto a suas políticas e programas de tecnologia (cujas razões são indicadas abaixo).

As atividades dos Estados Unidos orientadas para inovação, levadas a cabo por agências de segurança nacional, cobrem hoje um campo muito amplo, conforme mencionado anteriormente. A seguinte listagem (Weiss, 2012b) apresenta um breve resumo (indicando as siglas dos mais relevantes atores do NSS):

(1) Assumir contratos com o setor privado para fazer e comprar coisas que ainda não existem - isto é, "aquisição de tecnologia" [DOD, NASA, DOE];

(2) Prover "demanda garantida" para as inovações através de contratos de aquisição [de semicondutores a energias renováveis; por ex. DOD, NASA, DOE];

(3) Estabelecer "conjuntos de problemas" nos quais aqueles que desenvolvem tecnologia no setor privado possam trabalhar, resultando em geral em grandes avanços e novos setores industriais [ONA; DARPA; DOE; NIH];

(4) Financiar o desenvolvimento de invenções nos setores universitário e privado;

(5) Catalizar a formação de novas empresas [por ex. a SBIR é uma máquina de financiamento que investe até US\$3 bilhões anualmente em inovação de alto risco, mais que o dobro dos investimentos do setor privado de venture capital (VC), mais avesso a riscos, que se concentra em aquisições e fusões);

(6) Licenciar invenções criadas nos laboratórios nacionais para a indústria dos Estados Unidos; garantir direitos de patentes para invenções financiadas com verbas públicas [a cargo da NIH; DOD; DOE]; 
(7) Estabelecer a infraestrutura de base para a moderna indústria de VC turbinar as inovações [empresas de risco apoiadas pelo Estado, criadas na esteira do Sputnik, com uma alavancagem público-privada de US\$4,00 do governo federal a cada US\$1 investido pelo setor privado];

(8) Administrar empresas de VC com posições patrimoniais em startups selecionadas e empresas inovadoras [CIA; U.S. Army; DOE; DOD];

(9) Criar entidades híbridas que levem ao mercado invenções financiadas pelo NSS [inúmeros exemplos, que vão de financiamentos de risco a entidades de comercialização].

Apesar do alcance e do escopo de suas atividades (muito mais amplas que o foco convencional de gastos em P\&D), o NSS continua sendo subexaminado. As principais exceções (i.e. estudos que reconhecem o papel federal na inovação) foram muitas vezes orientadas por uma agenda de políticas -- ou limitando o papel de inovação do Estado a uma era passada (década de 1950 e 1960) ou, mais recentemente, priorizando o papel de agências civis como uma forma de "Estado Desenvolvimentista". Em cada um dos casos, o efeito é neutralizar a importância do papel de defesa/segurança que orienta a empresa de inovação. Em particular, nossos modelos de capitalismo comparativo nos serviram mal nesse domínio. Na verdade, ignoraram completamente a existência do NSS como uma instituição de tecnologia com inovação, na melhor das hipóteses reduzindo-o ao "militar" e portanto reduzindo convenientemente sua significância - como se o setor de defesa fosse desligado da economia convencional, nitidamente separado em seu próprio enclave. (A ideia de um "complexo militarindustrial" também contribuiu para esse conceito enganoso de enclave de um setor de defesa/segurança alijada da economia mais ampla.)

Examinando melhor a situação, não é de surpreender que os Estados Unidos tivessem inventado um modelo distinto orientado pelo Estado, de inovação orientada para segurança - um modelo que usa mais recursos, corre riscos mais altos, e produz muito mais inovações transformadoras (radicais?) que qualquer um de seus concorrentes. Olhando sob esse prisma, os Estados Unidos gastam aproximadamente 20 vezes mais que seus concorrentes, financiando, comercializando e contratando inovações do setor privado - hoje com tecnologias de duplo uso que se encaixam tanto no mercado comercial quanto no de defesa/segurança. Embora essa abordagem distinta resulte do fato de ser incorporada às motivações de segurança, mais uma vez deve-se enfatizar que ao longo das três últimas décadas, manter a supremacia exigiu mudanças na parceria público-privada. Por razões complexas, mudanças ligadas à natureza mutante e custos de tecnologia, ao espaço relativamente reduzido do mercado de aquisições referente à defesa, e às poucas vantagens para empresas privadas que trabalham em projetos de segurança nacional. Por todas essas razões, as agências de defesa e segurança tiveram de desenvolver novas formas para estender e 
aprofundar seus laços com o setor comercial e criar incentivos para atrair sua colaboração. Em particular, a nova abordagem incluiu estabelecer uma "viabilidade comercial" para atender aos requisitos tecnológicos do NSS, dando, portanto, às empresas privadas uma participação dos resultados. Sob esse aspecto, os Estados Unidos construíram um poder industrial em sintonia com (alguns diriam em razão de) seu militarismo, do qual emergiu um NSS com apoio e viés mais comercial (Weiss, 2012c).

Em termos mais genéricos, a crescente fusão dos objetivos comerciais e de segurança nacional produziu um modelo de desenvolvimento híbrido, no qual as linhas entre militar e civil, segurança e comércio, público e privado, ficaram bastante superpostas - e suas funções entrelaçadas. O entrelaçamento dos objetivos comerciais e de segurança é uma marca dos programas de investimento e aquisições do NSS: as agências nacionais de segurança e defesa atuam como "investidores anjos" e estrategistas de comercialização -- procurando transformar a propriedade intelectual criada publicamente em produtos lucrativos e indústrias viáveis. O DOE (por exemplo) usa sua verba para ajudar a retirar dos laboratórios inovações financiadas pelo governo federal para criar startups, enquanto o Centre for Commercialising Advanced Technology, de dupla face do DOD, olha para dentro a fim de cumprir suas missões de segurança e para fora a fim de promover produtos comerciáveis. Como "investidores anjos", as agências do NSS também assumem participações em empresas privadas para custear tecnologias comerciais de projetos relevantes para segurança, ou de duplo propósito. Tanto a CIA quanto o Exército, por exemplo, usam sua verba de VC para levar empresas novas a criar produtos relevantes para segurança que possam servir aos seus propósitos - além de desenvolver produtos viáveis para o mercado privado. Nas palavras do ex-presidente da In-Q-Tel, fundo de risco da CIA (que fez investimentos na Keyhole, mais tarde adquirida pela Google, por conta da sua tecnologia hoje conhecida como Google Earth):

“Nós não queremos que eles desenvolvam nada que seja destinado unicamente para o governo. Isso poderia levar a um produto órfão e não contribui para o sucesso da empresa. ${ }^{22}$

Ênfase semelhante pode ser encontrada na abordagem do Exército dos Estados Unidos com relação ao seu próprio fundo, o On Point, que focaliza poderio e energia móveis para o soldado. O Exército descreve seu fundo como "um investidor estratégico de risco" com "uma missão básica de facilitar o financiamento e criar produtos de duplo uso - produtos que atendem às necessidades de mercados comerciais privados, que também atenderão às necessidades do soldado individual..." ${ }^{\prime 23} \mathrm{O} V \mathrm{C}$ financiado pelo governo é, portanto, um dos vários desdobramentos da idéia de economia "independente do Estado" e do empreendedor sem suporte. Nessa abordagem de dupla face para atingir a supremacia tecnológica, a capacidade de produzir comercialmente produtos viáveis é hoje um critério-chave do apoio federal.

À medida que tais entidades públicas assumem funções do setor privado, muitas dessas criações instituídas federalmente podem ser consideradas "híbridos 
desenvolvimentistas". Nem estritamente públicas nem convencionalmente privadas, essas criações híbridas absorvem riscos através do ciclo de investimento, seja subsidiando ou investindo em pesquisa e desenvolvimento, seja voltando-se completamente para comercialização e marketing do produto.

O ponto mais abrangente que emerge da experiência dos Estados Unidos é que há um forte núcleo público ou "do Estado" no modelo americano, e sua maior motivação encontra-se na segurança nacional. Atingir a supremacia tecnológica (a fim de manter a primazia dos Estados Unidos), e não uma política industrial, tem sido sua força motriz. As origens desse sistema do pós-guerra estão na institucionalização do alerta permanente contra a guerra. Nos Estados Unidos, esse alerta permanente, por sua vez, criou um esforço de construção do Estado, que centraliza os empreendimentos de ciência e tecnologia dentro do Estado de Segurança Nacional (originando uma forma de "desenvolvimentismo da segurança"). O quê falta no Estado americano, porém, é uma ampla legitimidade política para um projeto desenvolvimentista que não militar ou de segurança. A governança industrial americana - que focaliza o crescimento de novos setores e tecnologias para promoção - em geral ocorre à distância da máquina convencional do Estado. A hibridização - que dá cobertura quase privada ou empresarial às atividades econômicas do Estado - cria mais uma camada que a afasta do olhar público. [Paul Volcker, ex-presidente do Federal Reserve, examina essa tendência à hibridização; em uma crítica recente ao envolvimento do governo federal no mercado de hipotecas, através da participação nas empresas Fannie Mae e Freddie Mac, ele argumenta que essas instituições "não deveriam existir", e acrescenta: "Ou vocês são uma entidade pública, ou privada. Se quiserem subsidiar o mercado de hipotecas, façam isso abertamente, não se escondam por trás de uma instituição quaseprivada."24

Em minha opinião, a hibridização é uma forma organizacional que parece particularmente apropriada para um ambiente político "antiestatista". O antiestatismo americano (que é institucional e também político) assegura que qualquer coisa que cheire a "política industrial", ou seja, direcionada para fins estritamente privados, cria forte oposição por parte dos conservadores, que derrubam prontamente essas iniciativas quando estão no poder. Porém a hibridização oferece uma forma de driblar o antiestatismo no contexto americano, atendendo tanto a objetivos comerciais quanto de segurança nacional. Isso talvez explique seu apelo bipartidário. ${ }^{25}$

Finalmente, vale notar que essa explicação não pretende sancionar um sistema de desenvolvimento industrial orientado para segurança. A versão dos Estados Unidos, é preciso dizer, mal leva em conta seus próprios custos e distorções. Mas essa é outra história (a que se conta usualmente). Atendo-nos ao assunto, o "desenvolvimentismo de segurança", apesar de todas as suas imperfeições vem oferecendo há várias décadas aos Estados Unidos um sistema formidável para produção de novas tecnologias e startups, criando mecanismos de crescimento através de novos mercados, e fornecendo uma plataforma de lançamento para suas empresas, em sua busca 
por mercados de exportação. Sob essa perspectiva, o Estado americano é mais "neoativista" que neoliberal - atuando para reger o mercado de tecnologia avançada. Acima de tudo, sua importância não passou despercebida aos estrangeiros, e Estados membros da União Européia, assim como a China, vêm prestando muita atenção aos americanos com vistas a adaptar aspectos do seu modelo de inovação. A China, em particular, moldou sua política governamental de aquisição a partir do modelo dos Estados Unidos de "compre produto americano", por exemplo, tirando do seu livro de regras a base para a definição do quê constitui uma empresa "chinesa" (e portanto eleita para tratamento preferencial).

Para concluir, os Estados Unidos talvez tenham perdido o brilho da sua marca ideológica - como líder do capitalismo de Livre Mercado - mas seu poderio militar e suas prioridades de segurança nacional permanecem excepcionalmente fortes. Por outro lado, é isso que continua a fornecer a catálise e o cadinho para sua capacidade de inovação tecnológica sem paralelo, que deu origem a inúmeras tecnologias revolucionárias, startups de alta tecnologia, e potencial para novos setores de crescimento na economia comercial. Contudo, a inovação não é uma panacéia para sanar o que aflige os americanos hoje. Eles se afligem porque a inovação tecnológica ocorre em um ambiente altamente financiado - o que é uma antítese do conceito de produção e trabalho, portanto, uma antítese da textura social para construção da nação. Isso não é de bom augúrio para o futuro. A inovação dos Estados Unidos foi profundamente infectada pela cultura do financiamento, em particular a queda dos custos para alimentar o apetite voraz dos acionistas por valorização do seu capital. Foi essa dinâmica financeira que, por sua vez, levou à produção offshore em busca de retornos maiores (embora uma visão pouco nítida culpe a "manipulação da moeda" da China pelo declínio da indústria americana). Por trás da estratégia offshore dos Estados Unidos, a maior meta corporativa não é reinvestir os lucros em especulações produtivas no mercado interno, mas buscar dividendos cada vez maiores para distribuir entre os acionistas - a ponto do valor de dividendos distribuídos ser na realidade mais alto que o valor dos lucros corporativos obtidos. Com a mania de terceirização, as empresas americanas desistiram da sua essência produtiva - à qual as empresas asiáticas se agarram. (Portanto, uma das primeiras perguntas que um investidor capitalista faz a uma startup é em que estágio do plano de negócios eles pretendem produzir offshore.) Os resultados dessa cultura do financiamento hoje são muito evidentes no crescimento sem um relativo aumento de empregos, e na divisão social para os que estão encapsulados na estatística do um por cento do topo da pirâmide. ${ }^{26}$

Assim, o desafio óbvio ao poderio americano hoje, pelo menos na superfície, é econômico. Os Estados Unidos têm de voltar ao crescimento, gerar empregos e cuidar do déficit. Mas o desafio econômico está intimamente ligado ao desafio político mais crítico, que é desalojar o imenso poderio da sua elite financeira. A elite financeira americana foi descrita com propriedade pelo ex-economista chefe do International Monetary Fund (IMF), Simon Johnson, como uma "oligarquia entrincheirada" que 
impede o avanço econômico e corroi a democracia americana ao comandar privilégios especiais e extraordinários - indistinguível das oligarquias corruptas que impediam desenvolvimento nas instituições pré-napoleônicas do Ancien Regime. ${ }^{27}$ Embora cada sociedade tenha suas elites, elas precisam ser mudadas de tempos em tempos. Os franceses que eliminaram sua nobreza, seu ancien regime, entenderam isso muito bem.

\section{Olhando na direção do "Sul": os BIC}

A grande ascensão das economias emergentes deveu-se à criação de novos mercados, empregos e crescimento. Envolveu também o pensamento independente sobre modelos de crescimento e a rejeição à visão do Consenso de Washington de que os mercados tinham melhor desempenho onde os governos governavam menos. Para os BIC não foi necessária a recente crise financeira para trazer o Estado de volta. Ao contrário, a perda de brilho do modelo americano substanciou e serviu para reforçar o quê os BIC vinham praticando já há algum tempo, antes do colapso de 2008 . Na maioria dos casos, eles vêm levando em consideração os mecanismos de crescimento partilhado, tais como redes de segurança social, educação e saúde, instituindo (ou reinstituindo) uma política industrial, e regulando os fluxos financeiros.

A estratégia inclusiva de crescimento do Brasil, por exemplo, conseguiu subir a renda per capita com reduções da desigualdade de renda. Entre 2003 e 2010, os 50 por cento mais pobres da população tiveram um aumento de renda de 69 por cento, e os dez por cento mais ricos um aumento de dez por cento. ${ }^{28}$ Apesar da redução da desigualdade continuar a ser um desafio, o esforço brasileiro contrasta dramaticamente com tendências dos Estados Unidos, onde o "crescimento" não representou aumento algum de empregos, e a renda deslocou-se grandemente para os dez por cento das famílias do topo da pirâmide (especialmente para um por cento do topo). O Brasil também rejeitou o fetiche de financiamento estrangeiro, impondo uma taxação de dois por cento sobre influxos de capital de curto prazo; e teve algum sucesso em refrear a especulação da moeda, elevando as exigências de reserva monetária dos bancos, e incentivando uma taxação sobre contratos futuros que competem com o real.

No domínio da governança industrial, a partir de 2003 o governo Lula restaurou a ideia de um papel mais ativo do Estado para promover o desenvolvimento, estabelecendo mais tarde mecanismos para coordenar a política industrial e para interagir com o setor empresarial. Até hoje, porém, parece que a abordagem da política enfatizou mais os cortes de impostos, para incentivar a produção e a exportação em indústrias de mão de obra intensiva, do que os incentivos para aumentar o upgrading de tecnologia e promover novos setores de crescimento. Aí também se inclui uma política de compras "Compre produto brasileiro" - uma versão do "Compre produto americano" dos Estados Unidos, vigente desde 1933 - que irá mudar as regras de compras públicas para permitir um tratamento preferencial aos fornecedores locais (por ex. o governo pode pagar até um quarto mais que o preço mais baixo do 
concorrente "estrangeiro", a fim de assegurar um fornecedor local). Mas a diferença básica é que tanto nos Estados Unidos quanto na China a compra governamental é orientada para a inovação; em outras palavras, o governo não está só comprando coisas da prateleira, mas também trazendo à tona novos itens que ainda não foram desenvolvidos (de locomotivas de alta velocidade a baterias tipo células a combustível e biocombustíveis a partir de algas). Essa abordagem de inovação não parece fazer parte da política de compras do Brasil.

Em contraste com o Leste Asiático, a ênfase permanente na mudança de estrutura industrial talvez seja o elo que falte na política industrial brasileira. O Brasil (como a Austrália, outro exportador de commodities) está aproveitando o boom das commodities por conta da China, e muitos alegam que isso faz subir o valor da moeda, deixando as exportações industriais sem competitividade e forçando a indústria a demitir trabalhadores (a chamada "doença holandesa"). Outros, mais notadamente o falecido Antonio Barros de Castro, argumentaram que mesmo com o controle da taxa de câmbio, é claro que a indústria brasileira continuaria sem poder de competição com a China, sugerindo a necessidade de uma abordagem mais proativa de inovação. ${ }^{29}$

Como bem se sabe, a liderança da China foi em muito baseada na abordagem de catch-up dos seus vizinhos do Leste Asiático, seguindo com afinco a estratégia tecno-nacionalista de subir na escada industrial através da aquisição agressiva de tecnologia e localização constante das capacidades de inovação. Por exemplo, ao preço de conseguir contratos para o sistema ferroviário de alta velocidade, a China forçou fabricantes estrangeiros de locomotivas, inclusive a Kawasaki do Japão e a Siemens da Alemanha, a oferecer seus designs recentes e a produzir 70 por cento de cada sistema localmente. Portanto, os fabricantes de locomotivas da China, de propriedade do governo, adquiriram tecnologias-chave e know how de fabricação - e o país construiu uma cadeia de fabricação de locomotivas. Em resultado, “hoje eles não só dominam o mercado da China como competem internacionalmente com as mesmas multinacionais que lhes forneceram o conhecimento e as competências em primeiro lugar". ${ }^{30}$ Como argumentou Barros de Castro, considerando o contínuo movimento ascendente da China, o Brasil terá de se reinventar com um máximo de esforço para construir valor naquelas áreas em que já tem uma vantagem competitiva. Barros de Castro pensa como um estrategista ED ao dizer que o Brasil deveria aplicar o conhecimento existente para explorar suas vantagens únicas - tal como fazer plásticos verdes da química do etanol - e deveria garantir a evolução do produto, estipulando que a indústria automobilística dos chineses (que deseja instalar-se no Brasil), use apenas plásticos verdes. Na realidade, ao focalizar um esforço de inovação nacional na criação de novas indústrias verdes, o Brasil poderia, dessa forma, utilizar seu enorme potencial de recursos ambientais e energia renovável, juntando-se (liderando?) a esforços globais para criar uma economia com baixa emissão de carbono. Isso significaria aprofundar a base de conhecimento, acrescentando um robusto pilar de inovação à sua estratégia de indústria de mão de obra intensiva. ${ }^{31}$ Porém, como nos 
lembra a experiência do Leste Asiático, quando os países se saem bem na política de inovação com indústria, em geral isso ocorre através da formação de redes públicoprivadas (que permitem o fluxo de informações para e do setor privado), e através da imposição de condições de desempenho aplicáveis aos objetos de apoio público.

\section{Conclusão}

Minha conclusão é que a capacidade de transformação dos Estados foi abandonada depressa demais, que o Estado realmente nunca "saiu dos negócios", e que o "Estado neoliberal" é na melhor das hipóteses uma ficção (será que necessária?) - até mesmo nos Estados Unidos, onde o neoliberalismo encontrou seu solo mais fértil. Precisamente por conta da integração econômica - e não apesar dela - a retirada do Estado da governança industrial foi sempre uma noção duvidosa, uma idéia promovida por uma confluência de ilusionismo conservador com uma supervalorização progressiva do alcance político do neoliberalismo.

Como mostram os casos aqui examinados, o Estado não voltou exatamente a ser redescoberto. Na verdade, as respostas recentes do Estado aos solavancos da integração global mais uma vez destacaram uma ideia já bem estabelecida, ou seja, o papel de mediação que o conjunto de valores nacionais e instituições domésticas como o Estado desempenha ao moderar pressões externas e moldar escolhas políticas. Como já vimos, mesmo em contextos marcados por um conjunto de valores antiestatistas, (mais notadamente nos Estados Unidos), o Estado foi uma máquina de crescimento orientado para inovação. Nesse caso, porém, a resposta às pressões externas foi a "hibridização" público-privada, levando o comércio a serviço da segurança - e a segurança a serviço do comércio. Muito dessa inovação orientada pelo governo, contudo, foi desconectada da indústria direcionada (financiada) ao mercado, esvaziando efetivamente a base produtiva. No Leste Asiático, onde a legitimidade do Estado é reforçada pela colaboração público-privada a fim de sobrepujar os rivais econômicos estrangeiros, os Estados remodelam suas estruturas industriais para continuarem a subir a escada econômica - e manter inovação e indústria intimamente ligadas no mesmo espaço nacional. Assim como os Estados desenvolvimentistas, nós também vimos que os BICs recorrem não apenas a uma tradição de pensamento econômico independente, como também a um conceito mais amplo do Estado como uma força positiva para promover desenvolvimento e moderar o impacto dos mercados globais. No Brasil,em particular, esse conceito do papel do Estado, por sua vez, deveria facilitar esforços estratégicos para mudar a estrutura industrial - se os formuladores de políticas assim escolhessem. 


\section{Notas}

1 O antiestatismo político chegou ao seu apogeu durante os anos da Guerra Fria, mas aparentemente teve raízes mais antigas, de origem geopolítica, quando a revolução bolchevique fez com que os republicanos se posicionassem contra o envolvimento do governo em assuntos econômicos. O antiestatismo foi mais fortalecido após a Segunda Guerra Mundial, como um estratagema politico planejado para distanciar o sistema americano (como um 'estado fraco' controlando os mercados livres) do sistema soviético (como um 'estado forte' controlando uma economia de planejamento central). Ver Cieply (2005). A campanha eleitoral de Ronald Reagan baseada na premissa de demonizar o governo, e não em fazer o governo funcionar melhor, teve um efeito particularmente devastador. Como observou Jeffrey Sachs, "Nenhum presidente desde então se desviou dessa linha". Até mesmo Bill Clinton declarou o fim do grande governo, e mais recentemente Rick Perry afirmou que quer tornar o governo federal o mais inconseqüente possível para o povo americano (Sachs 2011).

2 How did economists get it so wrong, New York Times, 2 de setembro.

3 Ver Dani Rodrik 2010: 'The Return of Industrial Policy', Project Syndicate, 12 de abril: http://www.projectsyndicate.org/commentary/rodrik42/English

${ }^{4}$ Citado em Dani Rodrik, 'The End of an Era in Finance', Project Syndicate, 3 nov 2010: http://www.projectsyndicate.org/commentary/rodrik41/English.

5 O estado americano, por exemplo -- o maior defensor mundial da não-intervenção no mercado ---tem um longo histórico em planejar resgates bancários, que vão dos esforços de Alexander Hamilton para deter o pânico no final do século dezoito, aos investimentos do governo feitos na Grande Depressão pela Reconstruction Finance Corporation (que adquiriu ações em cerca de 6000 bancos ao custo de aproximadamente US\$500 bilhões, no valor de hoje), e à mais recente aquisição de cerca de metade das instituições de Poupança \& Empréstimos da nação, na década de 1980 e início de 1990 (Weiss, 2012a).

6 Para uma argumentação detalhada ver Weiss (2012a).

7 Washington Post, 10 de outubro de 2008.

8 Vice-premier Wang Qishan, em uma entrevista à BBC, 2009.

9 Frances Fukuyama 2008: The Fall of America, Inc. Newsweek, 3 de outubro: www.thedaily beast.com/ newsweek/2008/.../the fall-of-america-inc.ht. .

${ }^{10}$ Elizabeth Thurbon (2011)

${ }^{11}$ Ver, por exemplo, Chalmers Johnson (1982).

12 Bruce P. Chadwick 2005: Information Technology Revolution in the Republic of Korea: Socio-Economic Development Issues and Policymaking Challenges. In A.Y. Mansourov (ed.), Bytes and Bullets in Korea, Asia-Pacific Center for Security Studies, Havaí

${ }^{13}$ Sung-Young Kim (2010).

${ }^{14} \operatorname{Kim}(2010: 12)$.

${ }^{15}$ Weiss (2005)

${ }^{16} \operatorname{Kim}(2010: 16)$

${ }^{17}$ Em 2008 o papel da política industrial do MIC passou para o recém-criado MKE, que também absorvia as antigas funções da política industrial de dois outros ministérios (Comércio Indústria, e Energia; e Ciência eTecnologia.

${ }^{18}$ Korea's Framework Act on Low Carbon Green Growth, cobrindo todas as facetas políticas de uma economia com baixa emissão de carbono, entrou em vigor no início de 2010.

${ }^{19}$ Citado em Glenn Fong 2001

${ }^{20}$ Minha pesquisa baseia-se em inúmeros relatórios do governo, documentos de agência federal, materiais do Congresso, e dados brutos da National Science Foundation, além de literatura secundária. Para a abrangente argumentação e fontes nas quais se baseia, ver Weiss (2012b): "Hybrid State, Hybrid Capitalism: National security roots of American innovation and enterprise". Livro ainda em manuscrito.

${ }^{21}$ Os outros componentes de NSS incluem o Department of Energy (DOE), NASA, National Institutes of Health (NIH), National Science Foundation (NSF), e mais recentemente o Department of Homeland Defense (DHD). Apesar de não convencionalmente agrupados sob a rubrica da NSS, há um corpo de trabalho significativo que discute suas funções relacionadas à defesa e segurança como agências individuais.

22 Mike Griffin citou em Michael Hardy 2003: "CIA funds not-so-secret investment funds", 4 de agosto, Federal ComputerWeek: http://www.fcw.com/print/9_28/nes/80460-1.html 
${ }^{23}$ US Department of Army: http://www.onpoint.us/about-us/index.shtml. As áreas de investimento que a OnPoint focaliza incluem energia nanossolar, células a combustível, e tecnologias de bateria portátil.

24 Paul A. Volcker 2011: Apresentação sobre saneamento das finanças dos Estados Unidos, International Herald Tribune, 24 de outubro, p. 18 [ênfase acrescentada]

${ }^{25}$ Para argumentação e pesquisa mais amplas nas quais se baseia, ver Weiss (2012b).

${ }^{26}$ Segundo os cálculos do Washington Post, em 2010 um por cento do topo da pirâmide representava um mínimo de US\$516.633, com uma riqueza média total de \$14 bilhões por pessoa. Ver Suzy Khimm, "Who Are the 1 Percent?", 6 de outubro de 2011. O Congressional Budget Office (2011) declara que entre 1997 e 2007 a renda cresceu em 275 por cento para as famílias que representam um por cento do topo da pirâmide de renda, e que a distribuição de renda de 80 por cento da população caiu de 2 a 3 pontos percentuais. Robert Reich faz notar que tanto as rendas como as riquezas concentraram-se no topo: "No final da década de 1970, cabia a um por cento dos americanos nove por cento da renda total e 18 por cento da riqueza da nação; em 2007, eles apresentavam mais de 23 por cento da renda total e 35 por cento da riqueza da América. Os CEOs da década de 1970 recebiam 40 vezes mais que a média dos executivos; hoje eles ganham 300 vezes mais que os executivos comuns". [Como resgatar o direito regressivo: http://news.salon.com/2011/10/17/how_to_beat_the_regressive_right/.]

${ }_{27}$ Johnson 2009: The Quiet Coup, The Atlantic. O colunista do New YorkTimes, Thomas Friedman, pronuncia-se ainda mais abertamente: O Congresso transformou-se em um fórum de "suborno legalizado", estima-se que a indústria de serviços financeiros gastou US\$2,3 bilhões em contribuições para campanhas federais de 1990 a 2010 - o quê corresponde a mais do que os setores de saúde, energia, defesa, agricultura e transporte juntos.

${ }^{28}$ Alfredo Cabal and Priya Shanker 2011: Brazil rising: The prospects of an emerging Power. Foresight, São Paulo.

${ }^{29}$ Entrevista com Claudia Antunes, 11 de abril de 2011: http://www.folha.com

30 Stephen Ezell, 2011: A Bretton Woods for Innovation. World Policy Journal, outono

${ }^{31}$ Claudio Frischtak (2011) argumenta que mesmo em casos nos quais o Brasil lidera a pesquisa científica (por exemplo, algumas safras de energia como a cana de açúcar), "o país permanece longe da sua capacidade". Em geral, ele acrescenta, os resultados em termos de ciência e inovação são incoerentes com os recursos naturais disponíveis, vantagens comparativas que surgem, e a necessidade de usá-las para dar ao Brasil também uma vantagem nas indústrias verdes e na sustentabilidade.

\section{Referências}

BLOCK, Fred 2010: The State of Innovation. Paradigm Publishers.

CHADWICK, Bruce P. 2005: Information and Communication Technologies and Economic Development in the Republic of Korea. In A.Y. Mansourov (ed) Bytes and Bullets: Information Technology Revolution and National Security on the Korean Peninsula, Asia-Pacific Center for Security Studies: Honolulu, HI: 52-69.

CIEPLY, David 2005: Why the State Was Dropped in the First Place: A Prequel to Skocpol's 'Bringing the State Back In'.

CONGRESSIONAL BUDGET OFFICE 2011: Trends in the Distribution of Household Income between 1979 and 2007. October. Washington DC. Online version.

FRISCHTAK, Claudio R. 2011:'Comparative Advantages, Innovation and Green Economy'.

FONG, Glenn R. 2001: ARPA Does Windows: The Defense Underpinning of the PC Revolution. Business and Politics, 3(3): 213-237.

JOHNSON, C. 1982: MITI and The Japanese Economic Miracle. Stanford University Press.

KIM, Sung-Young 2010: Transitioning from fast-follower to innovator: The institutional foundations of the Korean telecommunications sector, Review of International Political Economy, October: 1-29.

RODRIK, Dani 2010: The Return of Industrial Policy, Project Syndicate, 12 April. Online: www. project-syndicate.org/.../the-return-of-industrial-policy.

THURBON, Elizabeth 2011:'Why the Declinists are Wrong: (Mis)-Constructing the 1970s Authoritarian Korean State as The Developmental State Model.' Paper presented at the ISA 
Asia-Pacific Regional Section Inaugural Conference University of Queensland, September 29-30, Brisbane, Australia.

WEISS, Linda 2010: 'The State in the Economy: Neoliberal or Neoactivist?' In Oxford Handbook of Comparative Institutional Analysis, edited by John Campbell, Colin Crouch, Peer Hull Kristensen, Glen Morgan, Ove Kai Pedersen and Richard Whitley. Oxford: Oxford University Press.

WEISS, Linda 2012a: The Myth of the Neoliberal State. In Developmental Politics in Transition: The Neoliberal Era and Beyond, edited by Chang Kyung-Sup, Ben Fine, and Linda Weiss.

Macmillan Palgrave (in press).

WEISS, Linda 2012b: 'Hybrid State, Hybrid Capitalism: National Security Sources of American Innovation and Enterprise.' Book manuscript in draft.Weiss, Linda 2011c: Merging Commerce and Security through Innovation Hybrids. In Ronnie D. Lipschutz \& Shelley L. Hurt (ED) Hybrid Rule and State Formation: Public-Private Power in the 21st Century. Cambridge University Press (under review).

WEISS, Linda 2012c:'U.S. Technology Procurement in the National Security Innovation System. In Tarmo Kalvet, Rainer Kattel and Veiko Lember (eds) Public procurement for innovation policy: International perspectives. Springer Press.

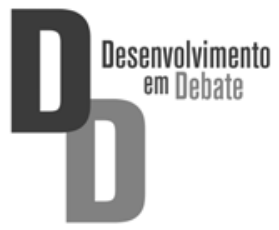

